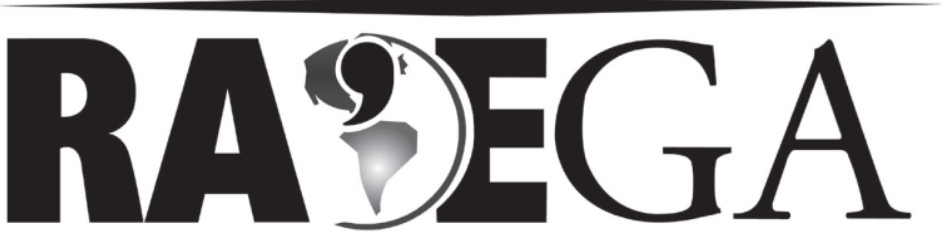

O ESPAÇO GEOGRÁFICO EM ANÁLISE

\title{
O PROCESSO DE EXPANSÃO URBANA E SEUS REFLEXOS NA REDUÇÃO DA COBERTURA VEGETAL NO MUNICÍPIO DE GOIÂNIA-GO
}

\section{THE PROCESS OF URBAN EXPANSION AND ITS CONSEQUENCES IN REDUCING OF VEGETATION COVER OF GOIÂNIA-GO}

\author{
Carolina Ferreira da Costa Streglio ${ }^{1}$ \\ Diego Tarley Ferreira ${ }^{2}$ \\ Ivanilton José de Oliveira ${ }^{3}$
}

\section{RESUMO}

Tendo em vista a relevância do processo de urbanização na composição da espacialidade contemporânea e o crescente anseio da sociedade por ambientes ecologicamente saudáveis, o presente artigo analisou, por meio de recursos disponíveis em Sistemas de Informações Geográficas (SIG), a relação entre o processo de urbanização e a redução da cobertura vegetal no município de Goiânia-GO. Na operacionalização do trabalho, a princípio realizou-se uma pesquisa documental, seguida da compilação da base cartográfica vetorial do município e do inventário de sua cobertura vegetal, no qual foram empregadas as imagens do sensor TM (Thematic Mapper), do satélite Landsat 5 , de órbita/ponto 221-71 e 221-72. Após a análise e o cotejamento dos dados obtidos, foi possível notar que, apesar das recentes iniciativas de proteção dos recursos naturais e da política de reforma e criação de parques urbanos, característica das últimas gestões municipais, nas duas

\footnotetext{
1 Mestra em Geografia, pelo Programa de Pesquisa e Pós-Graduação em Geografia, do Instituto de Estudos Socioambientais (UFG). Goiânia, Goiás, Brasil. E-mail: ocorreio@ymail.com

2 Mestre em Geografia, pelo Programa de Pesquisa e Pós-Graduação em Geografia, do Instituto de Estudos Socioambientais (UFG). Goiânia, Goiás, Brasil. E-mail: diego.tarley@gmail.com

3 Doutor em Geografia (USP), Professor do Instituto de Estudos Socioambientais (UFG). Goiânia, Goiás, Brasil. E-mail: oliveira@iesa.ufg.br
} 
últimas décadas a redução da cobertura vegetal no município de Goiânia continua avançando.

Palavras-Chave: Expansão Urbana; Cobertura Vegetal; Geoprocessamento.

\section{ABSTRACT}

In view of the relevance of the urbanization process in the composition of spatiality contemporary society and the growing desire for environmentally healthy environments, this paper analyzed through resources available in Geographic Information Systems (GIS), the relationship between urbanization and reduction of vegetation cover in Goiânia-GO. In the operationalization of work, I initially held documentary research, followed by the compilation of the vector base map of the city and the inventory of its forest cover, in which the images were employed Sensor TM (Thematic Mapper), Landsat 5, orbit / point 221-71 and 221-72. After the analysis and the comparison of the data obtained, it was possible to note that, despite recent initiatives to protect natural resources and the policy of reform and creation of urban parks, characteristic of the last municipal administrations in the last two decades the reduction of vegetation cover in Goiânia keeps advancing.

Keywords: Urban Expansion; Vegetation Cover; Geoprocessing.

\section{INTRODUÇÃO}

A urbanização constitui um dos processos mais marcantes na sociedade contemporânea. Segundo o Censo realizado pelo Instituto Brasileiro de Geografia e Estatística (IBGE), no ano de 2000, a população urbana brasileira era de quase 138 milhões de habitantes, o que correspondia a aproximadamente $81 \%$ da população. Atualmente, de acordo com os primeiros resultados do Censo de 2010, a população brasileira que reside em áreas urbanas ultrapassa os 160 milhões de habitantes o que representa cerca de $84 \%$ dos brasileiros.

À medida que o processo de urbanização avança, verifica-se também um considerável recuo da natureza, o que provoca não apenas uma expressiva perda de diversidade biológica, mas também contribui para a degradação do ambiente urbano. Diante disso, muitas propostas de ordenamento das cidades passaram a incluir a criação dos chamados parques urbanos com o intuito de 
melhorar a salubridade da cidade, além de proporcionar áreas de lazer à população citadina.

As diversas funções ecológicas (redução da poluição, proteção das nascentes e mananciais, moderação do clima urbano, manutenção da biodiversidade, dentre outras) e sociais (lazer, interação social, prática esportiva ou simples contemplação) atribuídas aos parques urbanos tornam esses espaços objetos de estudo de grande relevância para a compreensão da dinâmica urbana na atualidade, contexto em que se insere o município de Goiânia, capital do estado de Goiás.

Goiânia foi projetada em 1933, com base no modelo das cidades-jardins inglesas, concebido por Ebenezer Howard, em fins do século passado, o que refletiu no estabelecimento de diversas áreas verdes pelo município. Contudo, planejada para 50.000 habitantes, Goiânia ultrapassou essa marca já na década de 1950, quando percebia 53.389 habitantes (IBGE, 1950). Diante desse vertiginoso processo de crescimento do espaço urbano, resultando em um total de 1.301.892 habitantes em 2010 (IBGE, 2010), cabe questionar se aquelas áreas verdes previstas no plano original foram preservadas.

A partir da década de 1990, influenciada, principalmente, pelo movimento de proteção ao meio ambiente, a gestão pública de Goiânia passou a promover a reforma dos parques urbanos existentes, bem como a criação de novos parques por toda a cidade. Mas também é importante indagar se este seria um modo de corrigir os efeitos de uma possível expansão desordenada ou apenas uma estratégia para melhorar a qualidade de vida da população.

Tendo em vista essas inquietações, e considerando ainda que o uso de tecnologias na análise ambiental, além de permitir a ordenada aquisição de conhecimentos sobre a malha de relações naturais e socioeconômicas que incide em qualquer questão, possibilita também a integração entre os dados do ambiente físico e os dados socioeconômicos (SILVA; CALHEIROS, 2004, p. 66), neste artigo foi analisada, por meio de recursos disponíveis em Sistemas de Informações Geográficas (SIG), a relação entre o processo de urbanização e a redução da cobertura vegetal no município de Goiânia-GO. 
Para tanto, o trabalho se estruturou em dois eixos norteadores. Um primeiro visando a explanação do processo de crescimento urbano de Goiânia, retratando essencialmente o mapeamento da expansão de Goiânia, com base no ano de criação dos bairros. Por conseguinte, o segundo eixo se fundamentou na mensuração e análise da cobertura vegetal do município, tendo se baseado, para a cobertura original, em revisão bibliográfica (PDIG, 1992) e tratamento digital de imagens de satélite de 1986 (sendo a data mais coerente, considerando a disponibilidade de imagens e qualidade), e para a cobertura vegetal atual, imagens de satélite de 2010.

\section{ÁREA DE ESTUDO}

A cidade de Goiânia foi construída com o intuito de substituir a antiga sede do Poder Estadual, até então a cidade de Goiás. O processo de mudança da capital teve início em 20 de dezembro de 1932, quando o interventor assinou o Decreto $n^{\circ} 2737 / 1932$, nomeando uma comissão para a escolha do local. No dia 04 de março de 1933 foi apresentado um estudo selecionando a cidade de Campinas, tendo em vista que esta localidade possuía uma topografia adequada e promissora, em uma zona com maior desenvolvimento (devido a passagem da estrada de ferro), com um vasto perímetro de terras produtivas e cobertas por uma excelente mata (FERREIRA, 2003).

Partindo dessa conjuntura cresceu um grande município, que hoje se destaca no comércio, na oferta de ensino superior, na prestação de serviços públicos (principalmente os de saúde), na agropecuária e na indústria, que geram um Produto Interno Bruto (PIB) anual de $R \$ 17.867 .338 .000,00$, o que perfaz uma renda per capita anual de $\mathrm{R} \$ 14.355,00$, segundo dados do IBGE para o ano de 2007.

Em virtude desse expressivo crescimento, atualmente a capital juntamente com 19 municípios de seu entorno constituem a Região Metropolitana de Goiânia, conforme a Lei Complementar Estadual $n^{\circ} 78$, de 25 de março de 2010 (Fig. 1). Apesar do presente artigo abordar apenas o 
município sede dessa Região Metropolitana, é importante ressaltar esse processo de metropolização como a demonstração do atual estágio de urbanização do município de Goiânia.

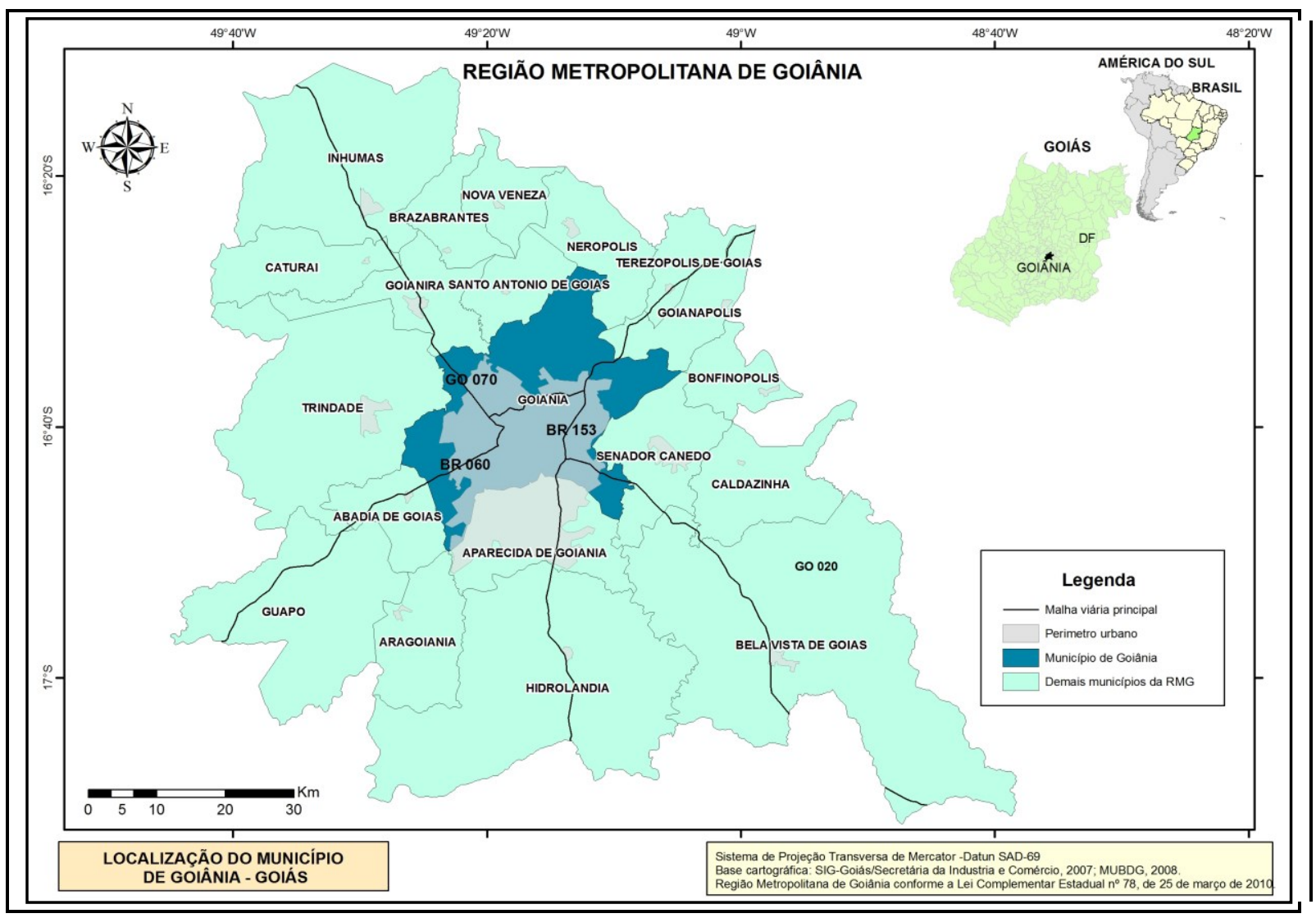

Figura 1 - Localização do município de Goiânia-GO.

\section{METODOLOGIA}

A fase inicial do trabalho consistiu em pesquisa documental, para análise da bibliografia existente sobre os temas urbanização, parques urbanos e outras temáticas correlatas, além da coleta de dados secundários em órgão públicos municipais, acerca desses temas.

Em seguida fez-se a compilação da base cartográfica vetorial do município de Goiânia, baseada no Mapa Urbano Básico Digital de Goiânia MUBDG, versão 21 - 2007. Essa base cartográfica foi inserida em um banco de dados geográficos em ambiente SIG, especificamente o software ArcGIS 9.3. 
O arquivo vetorial dos bairros de Goiânia foi editado, sendo incluídas as informações dos anos de criação dos bairros, com base nos dados secundários adquiridos junto à Prefeitura de Goiânia, por meio de sua Secretaria Municipal de Planejamento e Urbanismo (SEPLAM), e também do Instituto de Colonização e Reforma Agrária (INCRA).

O inventário da cobertura vegetal consistiu no tratamento digital das imagens de satélite, que se baseou no mapeamento da cobertura vegetal, no qual foram utilizados os software ENVI 4.3 e o ArcGIS 9.3, sendo o primeiro software utilizado para a classificação e o segundo para a correção, a mensuração e a finalização dos mapas.

Para tanto, foram empregadas as imagens do sensor TM (Thematic Mapper) do satélite Landsat 5, de órbita/ponto 221-71 e 221-72, que recobrem a área do município de Goiânia. As imagens foram obtidas no catálogo de imagens da Divisão de Geração de Imagens $(D G /)$ do Instituto Nacional de Pesquisas Espaciais (INPE), sendo logo em seguida, registradas (georreferenciamento), mosaicadas as cenas que recobrem o município e recortadas com base no limite de Goiânia.

No mapeamento da cobertura vegetal foi realizado o procedimento de classificação supervisionada de imagens orbitais - quando há definição de amostras das classes de cobertura do solo - sendo utilizado o algoritmo "mahalanobis". Após a classificação das imagens, processo este que nunca resulta em um produto $100 \%$ fidedigno (por conta da confusão espectral entre algumas classes), foi realizado um minucioso processo de inspeção visual, com exclusão, inserção e edição dos polígonos levantados na classificação supervisionada, utilizando-se as imagens orbitais em composição colorida RGB/5-4-3, do sensor TM do Landsat 5.

\section{RESULTADOS E DISCUSSÕES}

Para compreender a formação do espaço urbano de Goiânia é importante conhecer a dinâmica histórica que lhe deu origem. Nesse sentido há vários autores que definem períodos analíticos distintos, com vistas a essa 
caracterização, mas, geralmente, a base para esses estudos tem sido os planos diretores vigentes, responsáveis por nortear o desenvolvimento e crescimento do município, em conjunto com as leis de parcelamento e de uso do solo.

Segundo Ribeiro (2004, p. 37), Goiânia teve quatro 4 planos diretores em sua história, sendo apenas três deles oficiais:

o primeiro, concluído e oficializado em 1938, desenvolvido inicialmente pelo arquiteto e urbanista Attílio Corrêa Lima, de 1933-1935, e na sequência pelo engenheiro urbanista Armando de Godói, de 1935-1937; o segundo, não oficializado, desenvolvido pelo arquiteto Luís Saia, de 1959-1962 e que não teve a sua aplicabilidade e eficácia verificadas, devido ao momento político, a Revolução de 1964, que o tirou de cena, por considerá-lo produto de um comunista; e o terceiro real e o segundo oficializado em 1971, desenvolvido pelo arquiteto e urbanista Jorge Wilheim, de 1967-1969. O quarto [...] foi o da Engevix Engenharia S.A., desenvolvido de 1989-1992 e oficializado em 1994 (RIBEIRO, 2004, p. 37).

Relacionando a data de criação dos bairros de Goiânia com o período de vigência de cada um dos planos diretores foi possível identificar os efeitos dos referidos projetos na expansão urbana do município (Fig. 2).

4 Foram quatro planos diretores até o ano da referida publicação, ou seja 2004, entretanto no ano de 2007 foi oficializado um novo plano diretor, que atualmente encontra-se em vigor. 
RA'E GA 28 (2013), p.181-197

Curitiba, Departamento de Geografia - UFPR

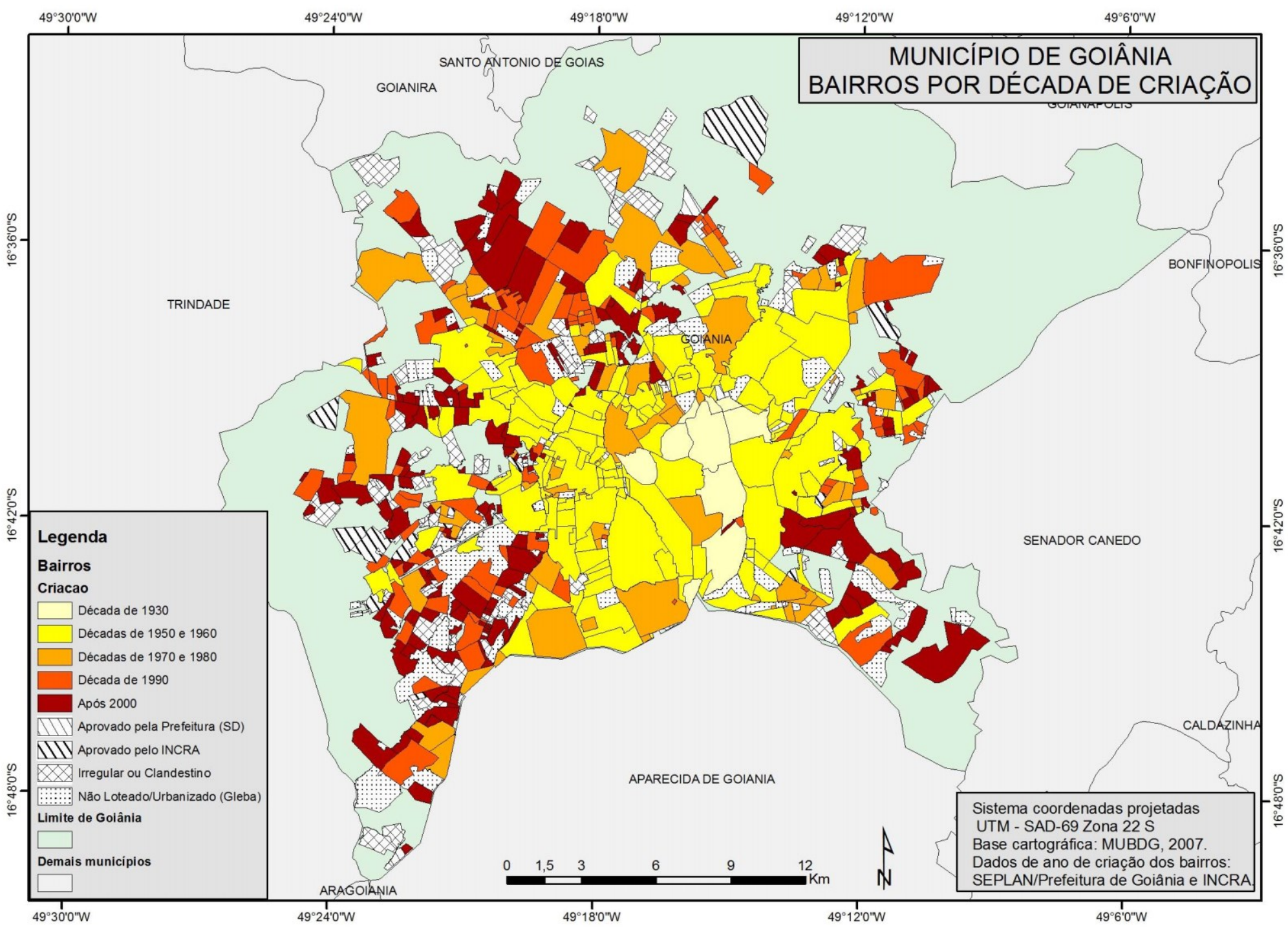

Figura 2 - Bairros de Goiânia-GO, por década de criação. 
No período que antecedeu a década de 1950, ou seja, a fase de vigência do primeiro plano diretor, percebe-se que poucos bairros foram criados (Tab. 1). Nessa época o Estado exerceu um papel preponderante na formação do espaço goianiense, estabelecendo um controle que garantiu a expansão da cidade conforme o plano então idealizado.

Tabela 01: Quantitativo de bairros conforme a década de criação.

\begin{tabular}{l|r}
\multicolumn{1}{c|}{ PERÍODO } & \multicolumn{1}{c}{ QUANTIDADE } \\
\hline Década de 1930 & 8 \\
\hline Década de 1950 & 126 \\
\hline Década de 1960 & 34 \\
\hline Década de 1970 & 34 \\
\hline Década de 1980 & 34 \\
\hline Década de 1990 & 102 \\
\hline Após o ano de 2000 & 180 \\
\hline
\end{tabular}

Fonte: SEPLAM/Prefeitura de Goiânia; compilado em ambiente SIG.

Entre as décadas de 1950 e 1960, em contraposição ao período anterior, houve uma explosão no ritmo de expansão, claramente expressa na Figura 2. Dentre os fatores relacionados a esse incremento no número de bairros, pode se mencionar a liberação do processo de parcelamento à iniciativa privada, a revogação da obrigatoriedade de implantação de infraestrutura urbana mínima para a instalação dos loteamentos e a inexistência de um plano diretor que regulasse o crescimento da cidade, visto que o plano de Luís Saia não chegou a ser executado.

De acordo com Ribeiro (2004, p. 95), nas décadas de 1970 e 1980, já sob as diretrizes do plano diretor elaborado por Jorge Wilheim e com a Lei de Loteamentos de 1971, Goiânia não expandiu significativamente seu espaço parcelado. Recorrendo novamente a Figura 2, percebe-se o surgimento de bairros situados em áreas distantes da região central da cidade, o que ocorreu 
devido o surgimento de conjuntos habitacionais destinados a população mais pobre. Segundo Ribeiro:

\begin{abstract}
Essa política tinha objetivos político-ideológicos muito claros de afastar a população pobre da cidade. Oferecer a ela apenas o lote, como era feito até então, era investir na possibilidade de seu retorno imediato da periferia ao centro, proporcional à falta de recursos urbanos disponíveis. Já instalá-la mesmo que precariamente em conjuntos habitacionais com um mínimo de infraestrutura, moradias de baixo custo relativo e alto alcance populacional atendia parcialmente aos objetivos de enraizá-la na periferia da cidade (RIBEIRO, 2004, p. 95)
\end{abstract}

A partir da década de 1990, com o plano diretor elaborado pela Engevix Engenharia S.A., o Plano de Desenvolvimento Integrado de Goiânia (PDIG/1992), alguns autores indicam que iniciou-se um novo ciclo de planejamento em busca pela reconstrução urbana de Goiânia, marcado pela integração do aglomerado urbano com a realização de projetos de transporte coletivo e pela inserção dos planos de lazer e de meio ambiente na pauta do planejamento (OLIVEIRA, 2007, p. 15).

Observando ainda a Figura 2, percebe-se que a partir do ano de 2000 o número de bairros volta a crescer, mas agora com os vetores de expansão apontando para as regiões sudoeste e noroeste da capital, localidades onde também se encontram um número significativo de glebas e bairros irregulares ou clandestinos (Tab. 2). Referente a esse período também é importante lembrar que em 2007 foi aprovado um novo plano diretor, então em vigência, e em 2009 foi lançado pelo Governo Federal o Programa Minha Casa Minha Vida, que deu um novo fôlego ao mercado imobiliário, além de financiar a construção de vários conjuntos habitacionais destinados a famílias de baixa renda, executados pelo Governo Estadual e pela Prefeitura nas regiões norte, noroeste e sudoeste de Goiânia. 
Tabela 02: Quantitativo de bairros conforme a situação no ano de 2010.

\begin{tabular}{l|r}
\hline \multicolumn{1}{c|}{ SITUAÇÃO } & \multicolumn{1}{c}{ QTDE. } \\
\hline Aprovados (sem data de criação) & 6 \\
\hline Aprovados pelo INCRA & 18 \\
\hline Irregulares ou clandestinos & 105 \\
\hline Não loteados/urbanizados (gleba) & 178 \\
\hline Regularizados (com data de criação) & 518 \\
\hline
\end{tabular}

Fonte: SEPLAM/Prefeitura de Goiânia; compilado em ambiente SIG.

Considerando os aspectos da expansão urbana de Goiânia, até então abordados, parte-se então para a representação da relação desse processo com a cobertura vegetal observada em Goiânia nos anos de 1986 e 2010 por meio das Figuras 3 e 4. 
RA'E GA 28 (2013), p.181-197

Curitiba, Departamento de Geografia - UFPR

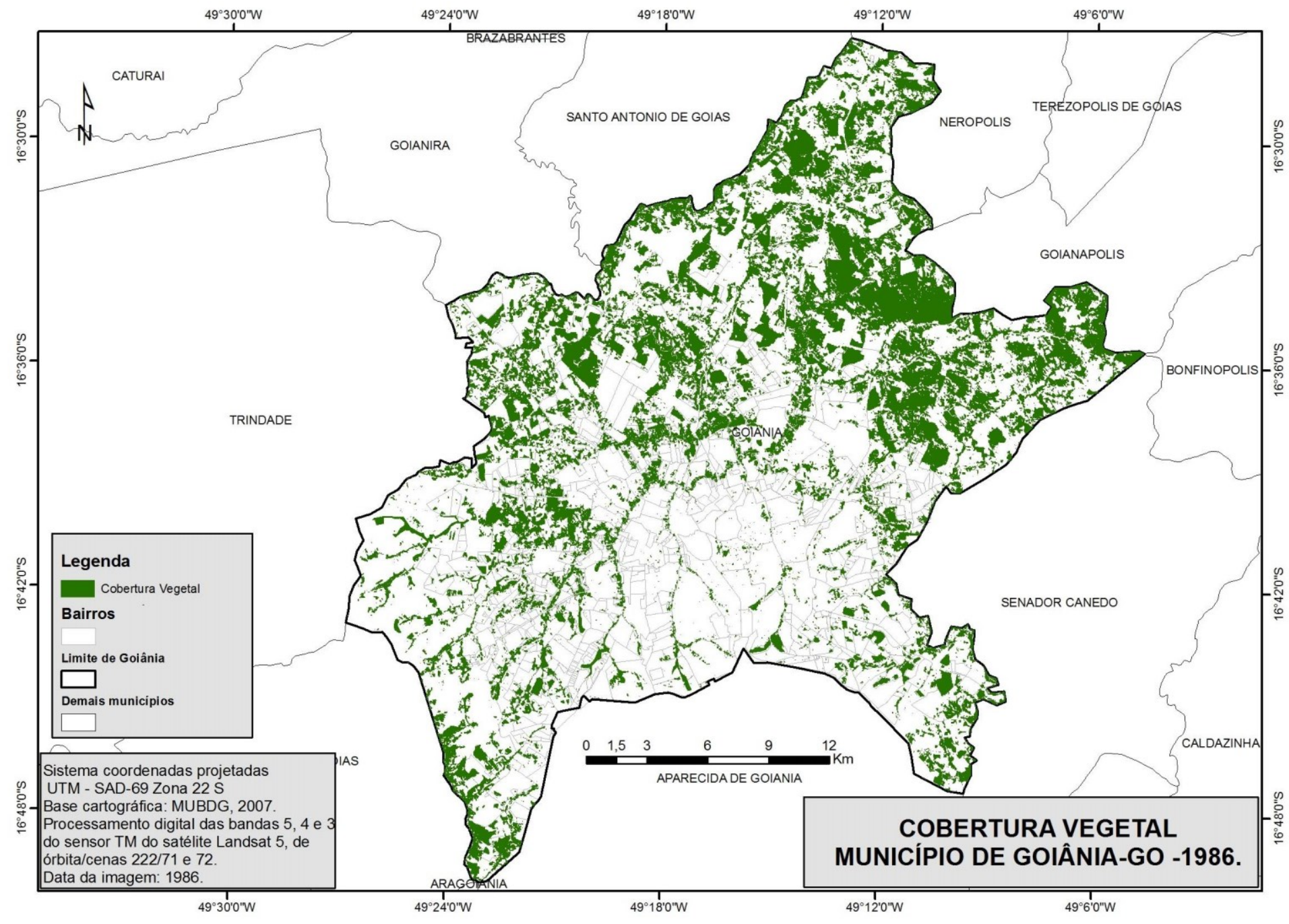

Figura 03 - Cobertura vegetal de Goiânia-GO, em 1986. 
RA'E GA 28 (2013), p.181-197

Curitiba, Departamento de Geografia - UFPR

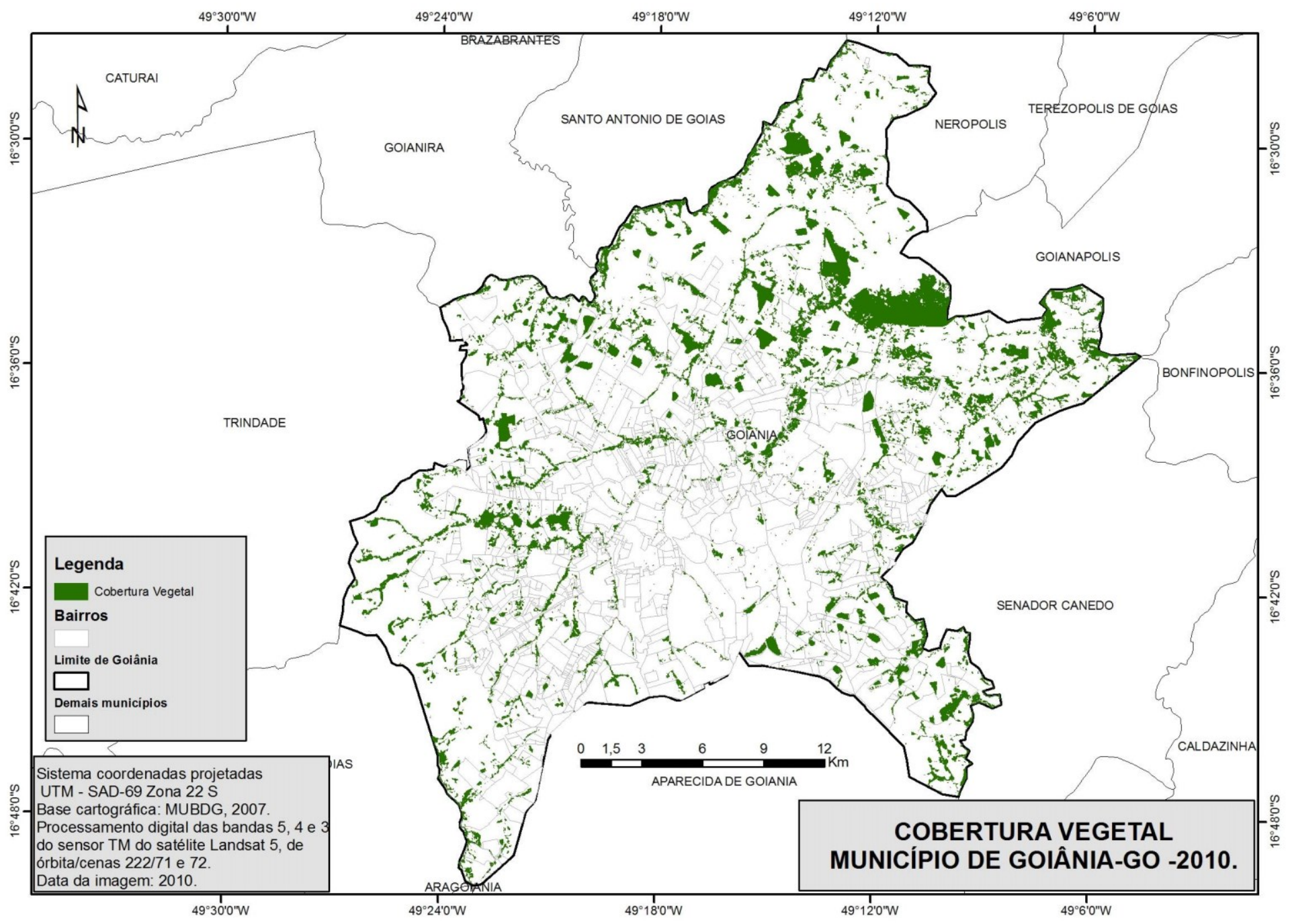

Figura 04- Cobertura vegetal de Goiânia-GO, em 2010. 
Conforme a quantificação realizada em ambiente SIG, no ano de 1986 a área revestida por cobertura vegetal em Goiânia era de 220,1 km², o que correspondia a $29,8 \%$ da área total do município, que possui $739,4 \mathrm{~km}^{2}$. Comparando as Figuras 2 e 3 nota-se que as porções de cobertura vegetal mais densas compreendidas na zona urbana da capital eram mais frequentes nos bairros mais distantes da região central de Goiânia, destacando aqueles situados à norte e noroeste. A caracterização realizada pelo PDIG/1992 indicou que quanto à vegetação originária, na década de 1980, havia menos de $6 \%$ da área total.

Mesmo as matas ciliares, essenciais a preservação dos cursos d'água, eram raras e, quando existentes, apresentavam um elevado nível de degradação. Havia apenas resquícios de cobertura vegetal original, formando manchas com dimensões variadas até o máximo de 400 hectares, que apareciam com maior frequência no quadrante nordeste do município, em virtude provavelmente das características do terreno da região, de relevo acidentado, impróprio ao uso urbano (RIBEIRO, 2004, p. 101-102).

Se naquela época a situação já era crítica, em 2010 os dados tornaramse ainda piores. De 1986 a 2010 a cobertura vegetal suprimida foi de aproximadamente de 52,7\% (Fig. 5), resultando num total remanescente de apenas 104,1 $\mathrm{Km}^{2}$. Analisando a Figura 4 observa-se que, além da intensa degradação ocorrida na zona rural, as áreas onde houve maior redução de cobertura vegetal apresentam uma significativa relação com as localidades onde foram criados bairros na década de 1990 e após o ano de 2000 (Fig. 2). 
RA'E GA 28 (2013), p.181-197

Curitiba, Departamento de Geografia - UFPR

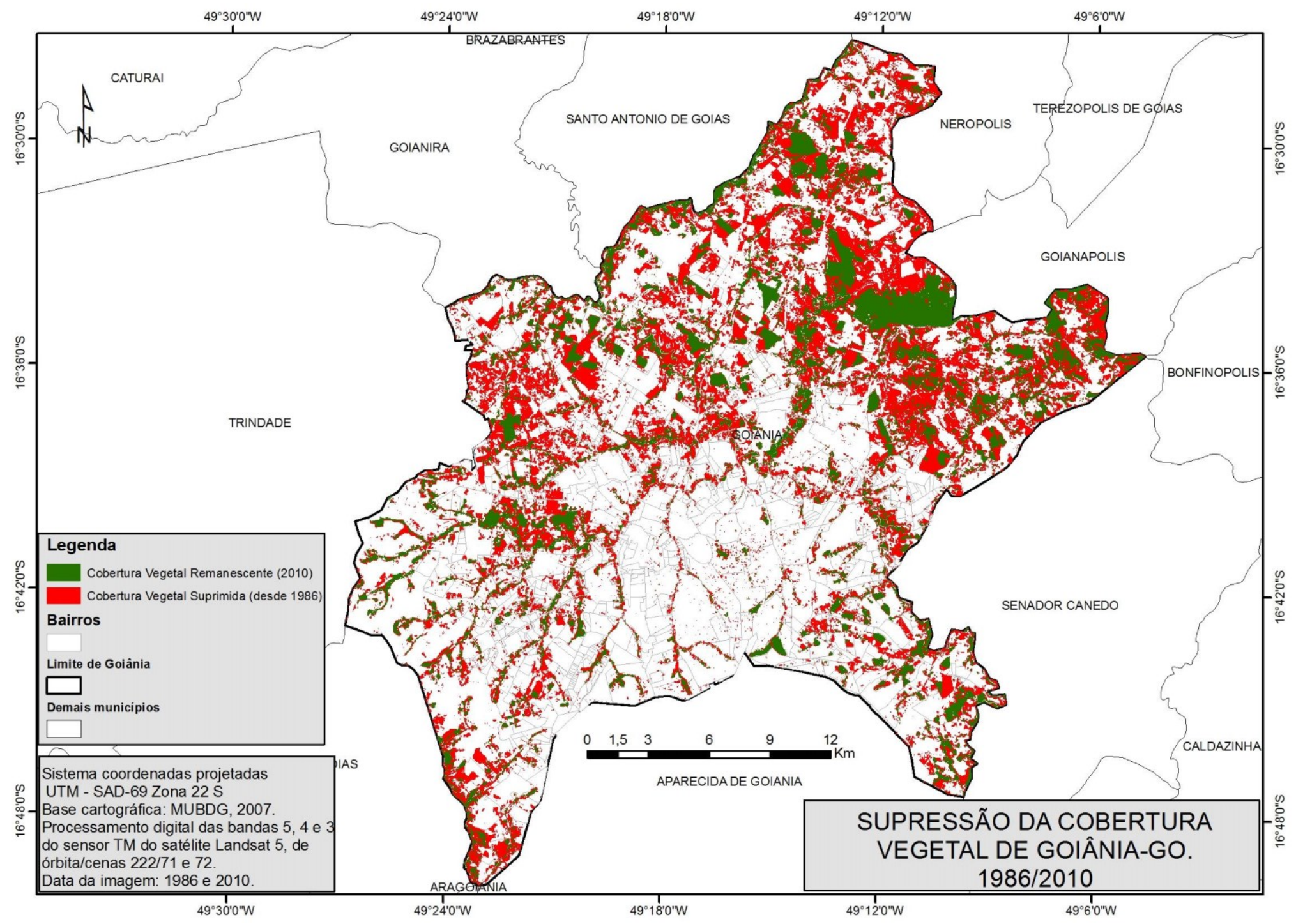

Figura 05 - Supressão da cobertura vegetal de Goiânia, de 1986 a 2010. 


\section{CONSIDERAÇÕES FINAIS}

Assim como outras grandes metrópoles brasileiras, Goiânia apresenta hoje muitos problemas que resultam de um processo de urbanização que, apesar de ter sido planejado, não foi executado de forma eficiente.

Como foi exposto, durante toda a história do município planos diretores foram elaborados, no entanto muitas de suas proposições ficaram apenas no papel, ou foram manipuladas conforme o interesse de grupos dominantes, em detrimento do interesse comum.

Por meio da representação gráfica e tabular foi possível notar que, apesar das recentes iniciativas de proteção dos recursos naturais e da política de reforma e criação de parques urbanos, característica das últimas gestões municipais, nas duas últimas décadas a redução da cobertura vegetal no município de Goiânia continua avançando.

Diante desse cenário, e considerando ainda as diversas questões ambientais e sociais que podem se agravar em decorrência de uma gestão municipal omissa e descompromissada com o bem comum, espera-se que as constatações expostas neste artigo possam subsidiar a pesquisa, o planejamento e a execução de políticas públicas comprometidas com a sustentabilidade e o desenvolvimento social.

\section{REFERÊNCIAS BIBLIOGRÁFICAS}

FERREIRA, Adriana dos Reis. A Compreensão do Lazer no Planejamento Urbano de Goiânia: aproximações históricas. Dissertação (Mestrado em Educação Física) - Faculdade de Educação Física, Universidade Estadual de Campinas. Campinas, 2003.

INSTITUTO BRASILEIRO DE GEOGRAFIA E ESTATÍSTICA (IBGE). Regiões de influência das cidades 2007. Disponível em: http://www.ibge.gov.br/home/geociencias/geografia/regic.shtm. Acesso em: 10.10. 2008. 
População: censos demográficos. Disponível em: http://www.ibge.gov.br/home/mapa site/mapa site.php\#populacao. Acesso em 14.01.2011.

OLIVEIRA, Adão Francisco de. A Reprodução do Espaço Urbano de Goiânia: uma cidade para o capital. Observatório das Metrópoles. Observatório das Metrópoles, 17 dez. 2007. Disponível em:

http://www.observatoriodasmetropoles.ufrj.br/download/go cid cap.pdf. Acesso em 25.09.2010.

INSTITUTO DE PLANEJAMENTO MUNICIPAL DE GOIÂNIA. Plano de Desenvolvimento Integrado de Goiânia. Goiânia: IPLAN, 1992.

RIBEIRO, Maria Eliana Jubé. Goiânia: os planos, a cidade e o sistema e áreas verdes. Goiânia: Ed. da UCG, 2004.

SILVA, Jorge Xavier da; CALHEIROS, Silvana Quintella. Geografia, análise ambiental e geoprocessamento: um esboço teórico. In: ARAUJO, Lindemberg Medeiros de. (org.). Geografia: espaço, tempo e planejamento. Maceió: UFAL, 2004. p. 59-68. 